\title{
A Brief Analysis of the Present Situation of the Research on Excessive Labor
}

\author{
Qiaolin Liu, Jinsong Pei \\ School of Economics and Management, Beijing Jiaotong University, Beijing, China \\ School of Economics and Management, Beijing Jiaotong University, Beijing, China \\ 15120556@bjtu.edu.cn
}

Keywords: Labor Economics. Excessive Labor. Overwork.

\begin{abstract}
The study of the problem of over labor in China is mainly derived from Japan, so the paper will separate Europe and the United States alone in the analysis of foreign research progress. For the convenience of comparison, the research of overwork problem in Japan and Europe and the United States are divided into three aspects, including Origin and definition of the study on overwork, focus of the overwork study and the influencing factors of the overwork. The paper elaborates the research status of China from five aspects, including origin, research object, measurement, influencing factors and the consequences. According to the data of "2015 China Labor Statistics Yearbook", finds that the research of China's overwork can be carried out from the following four aspects: expand and further the research object, standardize the excessive labor scale, increase the analysis factor of gender, strengthen the measuring analysis of the economic loss caused by overwork.
\end{abstract}

\section{Introduction}

According to the relevant regulations of the labor law, workers should not work more than 40 hours per week. However according to the 2015 Chinese Labor Statistics Yearbook, the average working hours of the urban employment are is more 46.6 hours. Among all industries, the proportion of working upper than 50 hours per week is more than $15 \%$. The proportion of working hours between 45 and 50 is $45 \%$. The proportion of working hours per week within the range 40 to 45 is $35 \%$. The percentage of working more than 40 hours per week in all the industries is about $95 \%$. As shown in Fig. 1. Weekly working hours in urban area by sector, studying on the problem of excessive labor is still worthy [1].

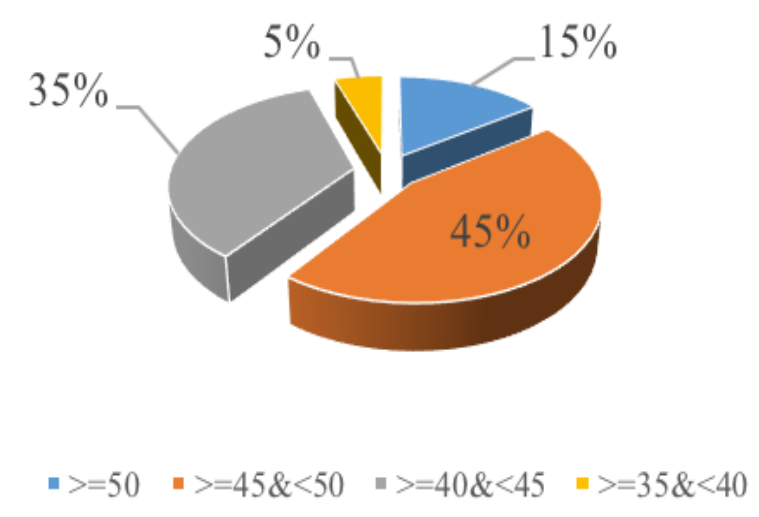

Fig. 1. Weekly working hours in urban area by sector

This paper agrees with Meng view on the overwork concept. There is such a state, super-intensity of labor in the work of the workers, and thus lead to fatigue accumulation. Even after a small amount of rest, workers can't restore the strength [2]. 


\section{Foundation of Excessive Labor Theory}

Assuming that the combination of capital and labor does not change and the labors can get the corresponding capital investment at any time, so changes in labor productivity will vary only with the changes in labor input. Thus, we can analyze the relationship between the labor productivity of single laborers and labor input. With the increase of the labor input of a single laborer, the laborer enters the working state gradually which leads to the increasing of labor productivity.

In the process of transition from labor shortage stage to moderate labor stage, find the highest labor productivity in moderate labor stage. Accompanied by the continuous increasing of a single laborer's labor input, laborer is in a state of fatigue, thus leads to the reducing of labor productivity. From unemployment state to moderate labor state, the labor input is insufficient. Beyond the moderate labor stage, still increase the amount of labor input. That will lead to extreme results which is called overwork death. The both sides of the moderate stage are different. On the one hand, part of the workers is deeply involved in excessive market competition. On the other hand, there is still part of the working age population free from the market competition. These two phenomena clearly coexist in China [3].

\section{Research Status of Excessive Labor in Foreign Countries}

3.1 Europe and the United States' Excessive Labor Research Situation. After twentieth Century, the problem of excessive labor of manual workers in Europe and the United States and other developed countries has been alleviated. Flora Stormer pointed out that the definition of excessive labor: "overwork phenomenon can't give a definition of persuasion, but generally understood as more than 40 hours of work per week whether employees, standard employment or nonstandard employment" [4].

European and American scholars' focus on the study of the problem is not full employment and the mismatch between excessive labor. Bell and Freeman pointed out that under intense competitive pressures, especially in the impact of labor market supply greater than the demand, workers had to work long hours to ensure that they were not fired. Campbell and Green showed more workers for a long time, more efforts have higher probability to get respect and recognition, and for promotion or right. Jacobs and Gerson argued that the attitude of workers, the expectation of higher status in the workplace, and the incentive mechanism of the enterprise will lead to excessive labor.

Europe and the United States has never stopped the analysis of the factors affecting the excessive labor. In 2008, Lonnie Golden published an article that analyzes the roots of workers' overwork from the perspective of a brief history of US working hours. The supply of worker labor time is defined as the expected number of working hours, in addition to economic factors such as wages and bonuses, cultural factors, personality characteristics, job promotion, job occupation development incentive value, workplace status, employer preference and society, these factors will affect the workers' expectation hours and cause workers to overwork [5]. In 2013, Cha from the point of the characteristics of the work, indicating that the different types of workers working hours there are differences in professional and management of the staff is more likely to over-labor situation [6].

3.2 Japan's Excessive Labor Research Situation. Japan's Professor Fineiron Cheng first proposed "overwork death" concept. In 1989, Japan from the medical view clear the meaning of "excessive labor" and "overwork death". Saito said that excessive labor is "the work of fatigue can't be restored the state by rest including sleep. And, "due to the balance of the nervous system disorders, triggering the organism homeostasis to maintain obstacles, the occurrence of irreversible changes ".

In order to understand the current situation of the work and life of the workers, the Institute of Labor Science has developed "the Index Number of Accumulated Fatigue Syndrome", which is composed of two parts: personal attributes and subjective symptoms. In 2004, the Central Labor Disaster Prevention Association developed, Japan Ministry of Health, Labor and Welfare promulgated the "Fatigue Accumulation Degree Diagnostic Scale." The scale consists of a self-diagnostic scale and a family diagnostic scale, which is the most widely used rating scale. 
At the beginning, the "reduced business" policy led to Japan's long, high-intensity labor. Japanese housing prices are high. In order to save the cost of living, workers living places and workplace distance is getting bigger. Commute time increases, so workers labor time increases. Now the family has gradually been included in the "enterprise society", the phenomenon of overwork death in the workplace is increasing. Later technological reforms, the combination of capital and labor, improved the efficiency of the workers but also allowed the workers to take higher intensity labor within the prescribed time. The flexibility of the Japanese employment form has increased the instability of the workers' work, and the employees have to accept prolonged overtime and high-intensity jobs [7].

\section{Research Status of Excessive Labor in China}

Excessive labor referred to as "overwork", China's initial study of excessive labor inspired by Japan. Ningying $\mathrm{Da}$ is the earliest concerned about the workers' over-labor scholars.

4.1 Research Object of Excessive Labor. In 2016, Dai narrowed the scope of research, deepened the research content to continue to university teachers as the object of study of excessive labor [8]. In 2016, Jiang from the perspective of econometrics analyzed the impact of labor remuneration on the excessive labor of migrant workers [9]. Printing enterprises employees, hotel employees, and other occupational burnout phenomenon have also been the focus of scholars.

4.2 Research on Excessive Labor Assessment. In terms of strain assessment, our country is experiencing from qualitative to quantitative, from full scale using Japan to the process of localization development scale. Along with the comprehensive and scientific concept of excessive labor, and the introduction of "Symptomatic Survey Scale", "the Index Number of Accumulated Fatigue Syndrome", "Fatigue Accumulation Degree Diagnostic Scale", measurement of excessive labor appeared in two dimensions: evaluation and evaluation of symptoms working condition.

4.3 Research on the Causes of Excessive Labor. In 2012, Meng etc. expounded from the unbalanced supply and demand in the labor market. They argued that the current labor market competition in China intensified, employers were in a dominant position, and labor bargaining power was almost lost before capital [10]. In 2014, Tong pointed out that the quality of the labor market is not balanced, the quality does not match, the employer's demand for labor quality surplus and the supply of labor quality is insufficient, and the employer can only extend the working hours or increase the intensity of work to get the proceeds, resulting in excessive labor [11].

4.4 Research on the Effects of Excessive Labor. From workers personally, excessive labor leads to mental disorders, the body disease, and serious conditions these three kinds of pathological damage. Zhang courageously summed up the adverse consequences of excessive labor, roughly divided into three aspects: enterprise cost increase, including safety accidents, employee turnover, etc.; Family harmony; Squeezing social livelihood issues, including employment, environmental pollution, etc. [12].

\section{Review of Research on Over Labor}

5.1 Domestic Excessive Labor Research Object Is Not Comprehensive, Not in-depth. As shown in Table 1. Weekly working hours in urban area by sector and sex, Hotels and Catering Services, Wholesale and Retail Trades, Services to Household\& Repair\& Other Services are the top three industries in the comparison of overtime hours according to "2015 China Labor Statistical Yearbook". Workers in Farming, Forestry, Animal Husbandry and Fishery sectors do not have excessive labor, and their working hours are within the statutory working hours. There may even be a lack of full employment. Labor resources in these industries may be in a state of inadequate use. 
Table 1. Weekly working hours in urban area by sector and sex

\begin{tabular}{|l|l|l|}
\hline \multicolumn{1}{|c|}{ Sector } & \multicolumn{1}{c|}{$\left[\begin{array}{c}\text { hours } \\
\text { /per week] }\end{array}\right.$} & $\begin{array}{l}\text { [exceed hours/ } \\
\text { per week }\end{array}$ \\
\hline Hotels and Catering Services & 51.6 & 1.9 \\
\hline Wholesale and Retail Trades & 50.5 & 1.1 \\
\hline Services to Household,Repair and Other Services & 50 & 1.7 \\
\hline Construction & 49.6 & 3.3 \\
\hline Manufacturing & 48.7 & 0.5 \\
\hline Transport,Storage and Post & 48.2 & 4.1 \\
\hline Information Transmission,Software and Information Technology & 47.6 & -0.8 \\
\hline Culture, Sports and Entertainment & 46 & 0.8 \\
\hline Mining & 46 & 3.9 \\
\hline Real Estate & 46 & 1.6 \\
\hline International Organizations & 45.2 & 10.8 \\
\hline Leasing and Business Services & 45.1 & 2.1 \\
\hline $\begin{array}{l}\text { Management of Water Conservancy, } \\
\text { Environment and Public Establishment }\end{array}$ & 44.8 & 0.4 \\
\hline Health and Social Service & 44.1 & 1.2 \\
\hline Production and Supply of Electricity, Heat, Gas and Water & 43.7 & 1.2 \\
\hline Financial Intermediation & 42.9 & 0.1 \\
\hline Education & 42.4 & 0.9 \\
\hline Scientific Research and Technical Service & 42.4 & 0.2 \\
\hline Public Management, Social Security and Social Organization & 41.9 & 0.9 \\
\hline Farming, Forestry, Animal Husbandry and Fishery & 37.4 & 5.3 \\
\hline
\end{tabular}

According to the above documents, it can be concluded that the current research object of excessive labor in China focuses on the mental workers represented by teachers and white-collar workers, as well as migrant workers and taxi drivers. Domestic research does not treat the above-mentioned serious excessive labor sectors as the object of overwork. Lacks profound and comprehensive overwork study on the severe overwork labor group.

5.2 Ignores Gender as a Factor in Excessive Labor. According to statistical data, in the same industry, the work hours that male labor time exceed female labor time is counted as "exceed hours/per week", draw Table 1. As shown in table 1. Weekly working hours in urban area by sector and sex, according to the"2015 China Labor Statistical Yearbook", finds that same industry gender but different gender will have a different overwork time. In the status of different industry and different gender, the difference is greater.

As a whole, the average weekly working hours of men are longer than those of women, except in the Information Transmission, Software and Information Technology sector. In International Organizations, the male's average labor hours per week than the female's is up to 10.8 hours. In the absence of excessive labor in Farming, Forestry, Animal Husbandry and Fishery sectors, the average male labor hours per week is more than 5.3 hours of women. Accordingly, this paper doubts that the employment rate of females in these sectors may be worse.

At present, there is a lack of in-depth research on regarding gender as a dependent variable in the overwork study. In addition to the social environment, the cultural system and the legal system, the different characteristics of the population will also have an impact on excessive labor. There are some differences for different group in the degree of overwork and the prevention and control of overwork. In 2005, Lee and Waite indicated that the degree of overwork among different gender is different. Men's work in general household is relatively less than women. However, men spend more time to support family, thus leads to overwork more easily.

5.3 Lack of Standardized Excessive Labor Scale. At present, there is lack of standardized and unified labor scale in China. So it is normal for referencing Japan's maturity scale in the process of practice. From the perspective of the research tools, scholars all believe that there is no uniform labor 
scale of overwork so far. In the formulation of the generally recognized excessive labor scale, it is necessary to refer to the make process of the Japanese labor scale. At the same time, it is also necessary to combine medical, legal and other interdisciplinary into the research. In addition, it is necessary to carry out a large number of industry characteristics of the empirical study. It is better to combine with the characteristics of various industries in China, so as to improve the scale on the basis of empirical research.

5.4 Lack of Quantitative Analysis of Excessive Labor. From the perspective of research content, there are many mature quantitative studies on the causes and consequences of overwork. On the research for causes of overwork, however, it lacks quantitative analysis for the impact of various factors by econometrics. Also lacks quantitative analysis for the economic loss caused by overwork.

\section{Conclusion}

Scholars in China have made great progress and achievements in the connotation, causes, formation mechanism and consequences of overwork, but there are still some gaps compared with developed countries. The existing research on overwork lacks attention on the characteristics and working characteristics of various labor groups. Can carry out a wide range survey to study the overwork for employment of all professions and trades, so as to grasp the status of overwork. By using the relative authority scale, can carry out an in-depth investigation to know well the status of domestic overwork. There exist different degrees of deviation between subjective judgment and objective measurement results of overwork, which makes the empirical research needs to be standardized and scientific. Increase and deepen the analysis of gender factors in the influencing factors of overwork. Analysis of the consequences of excessive labor must use scientific and reasonable methods of measurement to compute the economic loss caused by excessive labor.

\section{References}

[1] H. Yu: China Labor Statistical Year Book-2015(China labor social security publishing house, 2015).

[2] X.D. Meng: Study of causes excessive labor workers(Chinese Labor and Social Security Publishing House, China 2014).

[3] H.Q. Yang: China's labor problems are serious, urgent need to strengthen research(Population and Economy, China 2014), pp. 85-88

[4] F. Stormer: The Logic of Contingent Work and Overwork( Relations Industries, China 2008) pp. 343-361

[5] L. Golden: A Brief History of Long Work Time and the Contemporary Sources of Overwork( Journal of Business Ethics, America 2009), pp. 217-227

[6] Y.J. Cha: Overwork and the Persistence of Gender Segregation in Occupations(Gender \& Society, America 2013), pp. 158-184

[7] M. Koji: Era of overworking(Iwanami Shoten, Tokyo2009), p. 121

[8] Z.M. Dai: Problem and control strategy research a case study of University in Zhengzhou(Journal of Zhengzhou University of Light Industry College Young Teachers, Social Science Edition2016), p. 15

[9] R.Q. Jiang: Excessive impact on migrant workers labor remuneration(Research experience of Jilin University, China2016).

[10] X.D. Meng, H.Q. Yang: Evolution model and contemporary characteristics of working hours(economics and management research, 2012), pp. 85-90

[11] Y.F. Tong: Population aging process changes in labor supply in China and the challenges(Population and Society, 2014), p. 57 
[12] Z.Y. Zhang: Analysis of the formation mechanism of excessive labor(China Labor, 2015), pp. $23-26$ 